J. Clin. Chem. Clin. Biochem.

Vol. 18, 1980, pp. 255-256

\title{
SHORT COMMUNICATION / KURZMITTEILUNG
}

\section{Glucosebestimmung in Venen- und Kapillarblut mit der Glucosedehydrogenase-Methode in einer neuen Hämolysierlösung am AutoAnalyzer II}

Von W. Dick

\section{Zentrallaboratorium des Lukaskrankenhauses Neuß}

(Eingegangen am 7. August 1979/2. Januar 1980)

Zusammenfassung: Es wird eine neue Hämolysierlösung für die Glucosebestimmung mit der Glucosedehydrogenase-Methode am AutoAnalyzer II beschrieben. Außerdem wurde ein Vergleich mit einer anderen Hämolysierlösung (Boehringer) durchgeführt. Es ergab sich eine gute Korrelation der mit beiden Hämolysierlösungen erzielten Ergebnisse, aber eine bessere Haltbarkeit der Proben in der neuen Hämolysierlösung.

A new hemolysing agent for the determination of blood glucose (venous and capillary) by the glucose dehydrogenase method in the Autoanalyzer II

Summary: A new hemolysing agent is described for glucose determination with glucose dehydrogenase, using the Autoanalyzer II. The results correlate well with those obtained with a different hemolysing agent (Boehringer), but the new reagent improves the stability of the samples.

\section{Einfiihrung}

In unserem Laboratorium läuft seit 18 Monaten die Blutzuckerbestimmung mit der Glucosedehydrogenase-Methode im Hämolysat am AutoAnalyzer II. Die Methode erwies sich als einfach in der Handhabung, zeigte gute Haltbarkeit der Reagenzien und niedrigen Preis pro Analyse bei ausreichender Spezifität (2). Die einzigen Nachteille bisher waren die relativ geringe Haltbarkeit der Proben im Hämolysat und das Auftreten von Trübungen nach längerem Stehen. Deshạlb wurde eine neue Hämolysierlösung (3), die diese Nachteile nicht besitzt, für ihren Gebrauch auf dem Aưtọnalyzer II untersucht.

\section{Material und Methoden}

Geräte

AutoAnalyzer II (Technicon).

\section{Reagenzien}

1. Reaktionsgemisch

$0,12 \mathrm{~mol} / 1$ Phosphatpuffer pH 7,6

$0,15 \mathrm{~mol} / 1 \mathrm{NaCl}$

$5,2 \mathrm{kU} / \mathrm{h}$ Glucosedehydrogenase

$110 \mathrm{U} / 1$ Mutarotase

$1,1 \mathrm{mmol} / 1 \mathrm{NAD}^{+}$
2. Hämolysierlösung (neu, 1. c. (3))

$0,05 \mathrm{~mol} / 1$ Phosphatpuffer $\mathrm{pH} \mathrm{7,6}$

$1,0 \mathrm{~mol} / 1 \mathrm{NaCl}$

$2,8 \mathrm{mmol} / 1$ EDTA

$2,0 \mathrm{~g} / 1 \quad$ Tensid

3. Hämolyselösung (alt, 1. c. (1))

Siehe Arbeitsvorschrift Boehringer 1976.

Probenvorbereitung

$\mathrm{Zu} 1,0 \mathrm{ml}$ Hämolysierlösung als Vorlage in Eppendorfgefäßen gibt man $50 \mu l$ Blut und mischt gut. Die zur Kalibration verwandten wäßrigen Standardlösungen bzw. die für die Qualitätskontrolle benutzten Kontrollseren werden wie die Proben vorbereitet.

\section{Ergebnisse und Diskussion}

\section{Linearität}

Die Methode im neuen Hämolysat erwies sich als linear bis $24,9 \mathrm{mmol} / 1$ (450 mg/dl). Für den klinischen Bereich kann bis $27,8 \mathrm{mmol} / 1$ ( $500 \mathrm{mg} / \mathrm{dl})$ ohne Verdünnung gemessen werden, weil Proben dieser Konzentration nur um durchschnittlich 3,0\% zu niedrig bestimmt werden.

\section{Präżision}

Die Präzision ist, wie die Tabelle 1 zeigt, sowohl in der Serie als auch von Tag zu Tag zufriedenstellend.

Tab. 1. Präzision mit der neuen Hämolysierlösung.

\begin{tabular}{lclll}
\hline Präzision & Glucose & & VK & $\mathrm{N}$ \\
& $\overline{\mathbf{x}}(\mathrm{mmol} / \mathrm{l})$ & $\mathrm{s}(\mathrm{mmol} / \mathrm{l})$ & $\%$ & \\
\hline In der Serie & 5,42 & 0,073 & 1,36 & 55 \\
& 12,74 & 0,127 & 1,00 & 55 \\
Von Tag zu Tag & 5,45 & 0,101 & 2,10 & 10 \\
& 12,54 & 0,255 & 1,84 & 10 \\
\hline
\end{tabular}

\section{Richtigkeit}

Wie aus der Tabelle $2 \mathrm{zu}$ ersehen ist, ist eine gute Richtigkeit gewährleistet. Ein weiterer Wiederfindungsversuch mit wäßrigen Standards der Konzentrationen 2,77/5,54/11,1 und $16,65 \mathrm{mmol} / 1$ ergab eine Wiederfindung von $99,6 \%$ im Mittel $(98,5-101,3)$.

Tab. 2. Richtigkeit mit der neuen Hämolysierlösung.

\begin{tabular}{lccc}
\hline & $\begin{array}{l}\text { Sollwerte } \\
\text { (Glucose- } \\
\text { dehydro- } \\
\text { genase- } \\
\text { Methode) } \\
\text { [mmol/1] }\end{array}$ & $\begin{array}{l}\text { Glucose } \\
\text { gefunden }\end{array}$ & N \\
& [mmol/1] & \\
\hline $\begin{array}{l}\text { Control Serum N Roche } \\
\text { Lot. S 0836 }\end{array}$ & 5,49 & 5,42 & 55 \\
Monitrol II 51 B & 12,32 & 12,74 & 55 \\
Kontrollogen L 3106 & 5,38 & 5,40 & 10 \\
\hline
\end{tabular}




\section{Verschleppung}

Die Größe der Verschleppung wurde mit wäßrigen Standardlösungen der Konzentrationen 27,8 mmol/1 und 2,78 mmol/1 untersucht. Von der höheren zur niedrigeren Konzentration fand sich bei einer Probenrate von $60 / \mathrm{h}$ und $8 \mathrm{~s}$ Waschzeit eine Verschleppung von $2 \%$. Diese Untersuchung wurde entsprechend der Angaben von Hjelm (4) bzw. Haeckel (5) durchgefuihrt.

\section{Vergleich beider Hämoly șierlösungen}

Für diesen Vergleich wurden 190 Kapillarblutproben mit Glucosekonzentrationen zwischen $3,41 \mathrm{mmol} / 1(62 \mathrm{mg} / \mathrm{dl})$ und $27,31 \mathrm{mmol} / \mathrm{l}(492 \mathrm{mg} / \mathrm{dl})$ benutzt.

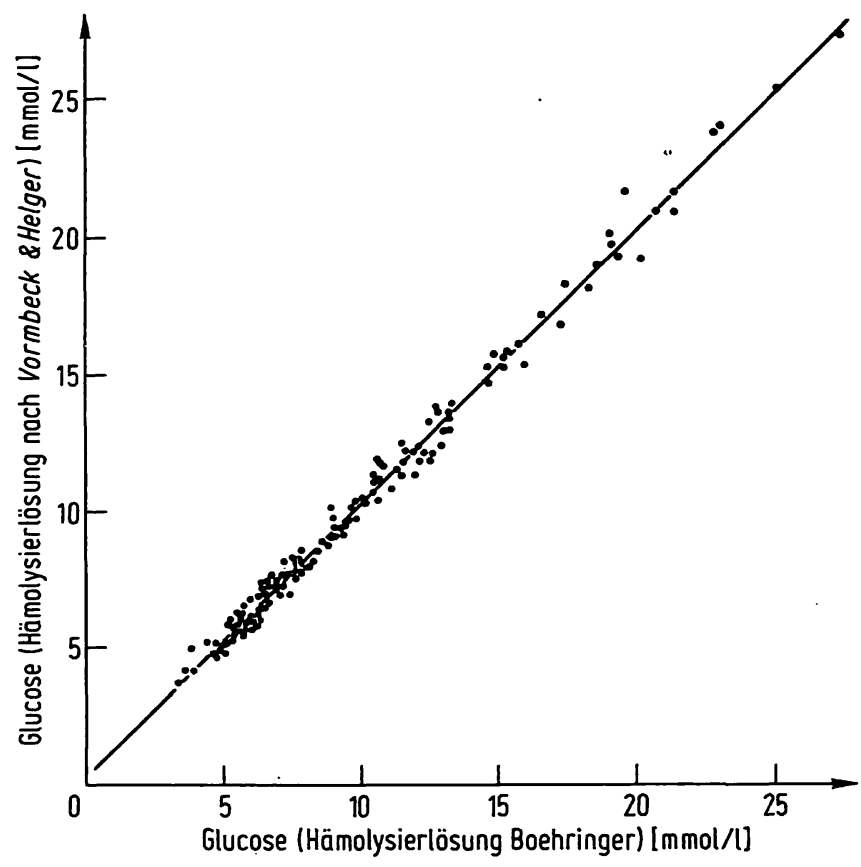

Abb. 1. Vergleich der Hämolysierlösungen.

Wie die Abbildung 1 bzw. die folgenden Daten zeigen, läßt sich zwischen beiden Hämolysierlösungen eine gute Übereinstimmung der Blutzuckerwerte finden.

$$
\begin{aligned}
x & =\text { Hämolysierlösung (alt) } \\
y & =\text { Hämolysierlösung (neu) } \\
N & =190 \\
y & =0,999 x+2,508 \\
x & =0,993 y-1,072 \\
r & =0,996 \\
\bar{x}-\bar{y} & =-2,28 \\
s_{y x} & =7,61
\end{aligned}
$$

\section{Haltbarkeit der Glucose im Hämolysat}

Die Haltbarkeit wurde bei Proben mit einem Glucosegehalt von $6,8 \mathrm{bzw} .14,4 \mathrm{mmol} / \mathrm{l}$ untersucht, und zwar bei $4^{\circ} \mathrm{C} \mathrm{bzw}$. $25^{\circ} \mathrm{C}$ gelagert.

Tab. 3. Haltbarkeit zweier bei zwei verschièdenen Temperaturen gelagerter Gilucoseproben.

Pröbe I $=6,8 \mathrm{mmol} / 1$ Glucose, II $=14,4 \mathrm{mmol} / \mathrm{l}$ Glucose

\begin{tabular}{llccc}
\hline $\begin{array}{l}\text { Lagerungs: } \\
\text { dauer }\end{array}$ & \multicolumn{2}{l}{$\begin{array}{l}\text { Glucose } \\
\text { [\% des Ausgangswertes] } \\
\text { Lagerung bei 4 }\end{array}{ }^{\circ} \mathrm{C}$} & \multicolumn{2}{l}{$\begin{array}{l}\text { Glucose } \\
\text { [\% des Ausgangswertes) } \\
\text { Lagerung bei } 25^{\circ} \mathrm{C}\end{array}$} \\
[h] & Probe I & Probe II & Probe I & Probe II \\
\hline 24 & 102 & 99,5 & 99 & 101 \\
48 & 100 & 103 & 102 & 98 \\
72 & 101 & 102 & 100 & 98 \\
96 & 98 & 99 & 97 & 99 \\
120 & 99 & 98 & 98 & 97 \\
\hline
\end{tabular}

Die in der Tabelle 3 aufgeführten Werte zeigen, daß die Proben in der neuen Hämolysierlösung sowohl bei $4^{\circ} \mathrm{C}$ als auch bei $25^{\circ} \mathrm{C}$ mindestens 5 Tage stabil sind. Dies läßt auf eine gute Hemmung der Glykolyse einerseits und eine zumindest ausreichende bakterizide Wirkung schließen. Im Gegensatz hierzu żeigt die altè Hämolysierlösung eine geringere Stabilität der Proben (siehe Firmenangaben Boehringer Mannheim, 1. c. (1)). Zur Vollständigkeit der Hämolyse ist zu sagen, daß im Gegensatz zur alten Hämolysierlösung innerhalb von 5 Tagen keine optisch wahrnehmbare Trübung feststellbar war.

\section{Literatur}

1. Boehringer: Analysenvorschrift für die Hexokinase-Methode am Autoanalyzer II (1976).

2. Banauch, D., Brümmer, W., Ebeling, W., Metz, H., Rindfrey, H., Lang, H., Leybold, K. \& Rick, W. (1975), Z. Klin. Chem. Klin. Biochem. 13, 101-107.

3. Vormbrock, R. \& Helger, R. (1979), Postervortrag Jạhrestagung 1979 der Österreichischen und Deutschen Ges. f. Klinische Chemie Salzburg. Abstract: J. Clin. Chem. Clin. Biochem. 17, 196.

4. Hjelm, H. (1975), Z. Anal. Chem. 243, 781-790.

5. Haeckel, R. \& Porth, A. J. (1972), Z. Klin. Chem. Klin. Biochem. 10, 91-94.

Dr. rer. nat. W. Dick Lukaskrankenhaus Zentrallaboratorium Preußenstraße 84 4040 Neuß 1 